\title{
Carbon dioxide storage in basaltic rocks: observations in natural systems vs laboratory experiments
}

\author{
PIERANGELO ROMANO ${ }^{1}$ AND MARCELLO LIOTTA ${ }^{2}$
}

${ }^{1}$ Istituto Nazionale di Geofisica e Vulcanologia - Palermo

${ }^{2}$ Istituto Nazionale di Geofisica e Vulcanologia- Palermo

Presenting Author: pierangelo.romano@ingv.it

Nowadays carbon dioxide removal from atmosphere is the most ambitious challenge to mitigate climate changes. Almost 10 years ago started the first pioneering projects of carbon storage in mafic and ultramafic rocks. Basalt rocks are abundant on Earth surface $(\approx 10 \%)$ and very abundant in the ocean floors and subaerial environments. Glassy matrix and minerals constituting these rocks contain metals $\left(\mathrm{Ca}^{2+}, \mathrm{Mg}^{2+}, \mathrm{Fe}^{2+}\right)$ that can react with carbonic acid to form metal carbonates $\left(\mathrm{CaCO}_{3}, \mathrm{MgO}_{3}\right.$ and $\mathrm{FeCO}_{3}$ ). If $\mathrm{CO}_{2}$ dissolves in water this process is accelerated and it commonly occurs in environments where water circulates in basaltic aquifers. Here we present a data compilation of chemical composition of waters circulating in basalt aquifers worldwide. Induced or naturally occurring weathering of basalts rocks release elements in waters and elemental concentration is strictly dependent on water $\mathrm{CO}_{2}$ concentration (and hence on water $\mathrm{pH}$ ). For instance, first observations suggest that element concentrations result higher in water circulating in basalt aquifers of active volcanic systems (i.e. Etna, La Reunion). Laboratory experiments (Galeczka et al., 2013 and reference therein) have evidenced that in the first stages of water-rock interaction the high content of $\mathrm{CO}_{2}$ dissolved in water accelerate the basalt weathering process releasing in water not only elements that can form carbonate minerals but also other elements which depending on their concentration can be essential or toxic for life. These elements, depending on their mobility, can be fixed in other mineral phases or remain in solution. The final aim of this study is the to compare experimental findings and natural evidences to better understanding the processes in basaltic aquifer hosted in active and inactive volcanic systems. Results will be discussed in light of the potential environmental impact of $\mathrm{CO}_{2}$ storage in mafic and ultramafic rocks.

Galeczka et al., 2013. Experimental studies of basalt-H2O$\mathrm{CO} 2$ interaction with a high pressure column flow reactor: the mobility of metals. Energy Procedia 37 (2013) 5823 - 5833. 